\title{
Research on Mechanical Properties of Cement-gravel Core Material
}

\author{
Zhong Liü, ${ }^{1, a}$, Ruishe Qiao ${ }^{1, b}, \mathrm{Na} \mathrm{Li}^{1, \mathrm{c}}$, Bojin $\mathrm{Hao}^{1, \mathrm{~d}}$, Yuqin Gao ${ }^{1, \mathrm{e}}$ \\ ${ }^{1}$ Yellow River Institute of Hydraulic Research, YRCC, Zhengzhou 450003, China; \\ aliuzhong200707@163.com, ${ }^{b}$ rsqiao@163.com, 'zhuofan8227@163.com, dhbojin@163.com, e gao \\ qin205@163.com
}

Keywords: high earth-rockfill dam, cement-gravel core material, cement mixing ratio, mechanical property

\begin{abstract}
Cement-gravel core material with clay cement and gravel as the primary ingredients is a new core material for embankment dam, and it is generally perceived to have broad applications in the field of dam construction since the stress-strain behavior of such core material is between gravelly soil core and rockfill. Through the triaxial CD test of this material with different cement mixing ratios $\left(w_{c}\right)$, the effect of cement mixing ratio on the stress-strain behavior is experimented. The results indicate that the axial deviatoric stress-axial strain and volumetric strain-axial strain curves of this material exhibit softening and dilatancy in different degree respectively as cement mixing ratio increasing. Given the same cement mixing ratio, the peak strength performs almost linearly with an increase of confining pressure. The same pattern is also applicable to the internal friction angle as cement mixing ratio increasing. In addition, the cohesion and secant modulus significantly increase as cement mixing ratio increasing. The research results can provide limited technical support for mechanical properties of cement-gravel soil applied to the core material of high earth-rockfill dam.
\end{abstract}

\section{Introduction}

The design of earth-rockfill dam has received intense public attention as damming material could be easily obtained from local sources. This type of dam is highly appreciated due to its strong deformation capability and aseismatic performance.In recent years, with the rapid development of high earth-rockfill dam in China, many earth-rockfill dams with over 200m height have been designed or under construction, for example Nuozhadu $(263.5 \mathrm{~m})$ and Shuang jiangkou (316.0m). Higher requirements for the design and construction of such dam have been set, then an engineering problem needs to be solved urgently which is how to effectively reduce the arch effect of core wall. Since the arch effect of core material is directly related to the resistance against hydraulic fracture, the performance of core material under such scenarios has received wide attention in the field of engineering[1-2].

Numerous studies had been done by many researchers to obtain high deformation modulus of core material so as to reduce inhomogeneous deformation and the arch effect and to avoid the hydraulic fracture of the core wall[3-6]. Currently, a common solution is to mix coarse-grained material with fine grained-soil, also known as gravelly soil core material. However, for dam with the height of over $200 \mathrm{~m}$, the arch effect of core could be highly intense, which is bad for the anti-hydraulic performance of core material since the deformation modulus between the gravelly soil core and rockfill material is relatively large[7]. Adding more gravel to fine grained-soil would doubtless increase the deformation modulus of core wall, but the permeability may not meet the requirements under small deformation. Therefore, it is worthwhile to study how to enhance the deformation modulus and reduce the arch effect of core wall.

Wu et al.[8] invented a new material used for constructing dam with high deformation modulus and using economically, which is similar to lean concrete except that its permeability fails to meet the requirements.

Another case in point is cement stabilized gravelly soil used as the subgrade fill or backfill of bridgehead in the field of highway engineering [9-10], in other words, the deformation modulus of this material is improved because of cement added to gravelly soil. Moreover, cut-off wall [11-14] 
made from plastic concrete (i.e., a mixture of cement, clay and sand gravel) is also a successful application for many water conservancy and hydropower projects. The commonness among all these applications is that their modulus has increased for cement added to gravel and (or) soil. Further research is needed to study that the mechanical property of core material mixed with a certain amount of cement could be improved and thus replace the common core material. In this paper, the method of certain amount of cement into gravelly soil is proposed in order to enhance the mechanical performance of core wall, to improve the strength and deformation modulus of core material, to reduce the arch effect within core wall and to meet the seepage requirements. A series of studies should be carried out to determine the proportion of cement to achieve better performance of core material.

Therefore, cement-gravel soil was proposed as a new mixture which is composed of cement gravel and clay. And gravel and clay came from some core material as the primary ingredient The stress-strain behavior and strength characteristics of cement-gravel soil were investigated using the triaxial CD tests with the various cement mixing ratios.

\section{Material and testing scheme}

The medium triaxial apparatus (specimens are with a diameter of $101 \mathrm{~mm}$ and a height of $200 \mathrm{~mm}$ ) was adopted in the laboratory. Clay with a liquid limit of $34.8 \%$, a plasticity index of $19.4 \%$ and a specific gravity of 2.61 was taken from core material. The grain-size distribution for gravel and gravelly soil is shown in Table 1.

Table 1 Grain-size distribution for gravel and gravelly soil (unit: \%)

\begin{tabular}{ccccc}
\hline Material & $20 \sim 10 \mathrm{~mm}$ & $10 \sim 5 \mathrm{~mm}$ & $5 \sim 2 \mathrm{~mm}$ & $<2 \mathrm{~mm}$ \\
\hline Gravel & 61.15 & 26.85 & 12.00 & 0.00 \\
gravelly soil & 18.35 & 8.05 & 3.60 & 70.00
\end{tabular}

After clay baking and comminuting, clay, cement and gravel were mixed according to the defined mixing ratio. Water was then added and mixed well with clay, cement and gravel. After 30-45mins, the mixture was divided and put into five tube layers, and the mixture from each tube was then compressed up to the preset density.

The used cement was normal $325^{\#}$ Portland cement, and the amount of cement was determined by the mixing ratio $w_{\mathrm{c}}$ (the weight of cement over that of dry clay). Gravelly soil with different cement-mixing ratios (i.e., $w_{c}$ as $3 \%, 5 \%$ or $8 \%$ ) was tested. Since cement would absorb water during the hydration process, and the specimen was likely to get fully compacted with the ideal amount of water. The total amount of water required included the ideal amount of water for solid-compacted and the amount of water for the hydration of cement. Water to cement ratio (i.e., the weight of water over the weight of cement) was set as 0.4 with the entire hydration conditions taken into account.

The optimum moisture content and the maximum dry density were determined by light-weighted compaction test according to specific protocols [15]. Meanwhile, gravels (30\% of the total weight of gravel and dry clay), dry clay, cement (with three different mixing ratios, namely, 3\%, 5\% and $8 \%)$ and water were well-mixed. Test samples were prepared, and their density was 0.96 times of the maximum dry density of the fabricated mixture. The dry density of the mixture was $1.854 \mathrm{~g} / \mathrm{cm}^{3}$.

After the sample fabrication procedure, samples cured under room temperature for $24 \mathrm{~h}$ and then were demolded. All samples were sealed using plastic bags, and put into the standard curing box for 7 days. Then, all samples underwent processes of vacuum saturation, isotropic consolidation and shearing behavior with the shear rate as $0.016 \mathrm{~mm} / \mathrm{min}$.

The gravelly soil (shown in Table 1) with the proportion of gravel as $30 \%$ was tested using four schemes, namely $\mathrm{M}_{30-0}, \mathrm{M}_{30-3}, \mathrm{M}_{30-5}$ and $\mathrm{M}_{30-8}$ corresponding cement mixing ratio $0 \%, 3 \%, 5 \%$ and $8 \%$, respectively. Four specimens in each group were used for each test, with confining pressures as $200 \mathrm{kPa}, 500 \mathrm{kPa}, 800 \mathrm{kPa}$ and $1200 \mathrm{kPa}$, respectively. 


\section{Test results and analysis}

Stress - strain characteristics. Figure 1 shows the axial deviatoric stress $\left(\sigma_{1}-\sigma_{3}\right)$ - axial strain $\varepsilon_{\mathrm{a}}$ and volumetric strain $\varepsilon_{\mathrm{V}}-$ axial strain $\varepsilon_{\mathrm{a}}$ curves with different cement ratio $w_{\mathrm{c}}(3 \%, 5 \%, 8 \%)$ and different levels of confining pressure of cement-gravel soil under the $30 \%$ gravel content. For comparison purpose, the relationship curve of gravelly soil without cement is shown in this figure. The interpretation of the curve number 30-3-200 is: 30 represents the proportion of gravel in the mixture, cement ratio 3 represents 3\%, and 200 represents $200 \mathrm{kPa}$ confining pressure.

It can be seen from Figure 1 that the relationship( $\left.w_{\mathrm{c}}=3 \%\right)$ between $\left(\sigma_{1}-\sigma_{3}\right)$ and $\varepsilon_{\mathrm{a}}$ is the strain hardening type under different levels of confining pressure. But when the confining pressure is $200 \mathrm{kPa}$, the relationship between $\varepsilon_{\mathrm{v}}$ and $\varepsilon_{\mathrm{a}}$ displays shear dilatation characteristic, whereas their relationship would exhibit shear shrink characteristics under other levels of confining pressure. As $w_{\mathrm{c}}$ increasing, the softening phenomenon regarding the relationship between $\left(\sigma_{1}-\sigma_{3}\right)$ and $\varepsilon_{\mathrm{a}}$ has been gradually strengthened, whereas the soften transition section has been gradually steepened.

Other curves do not show obvious fold points. Instead, they generally display a smooth hump shape. The plastic deformation and failure pattern is similar to the case of over-consolidated stress-strain curve for soil, except that the $\left(\sigma_{1}-\sigma_{3}\right)-\varepsilon_{\mathrm{a}}$ curve of sample with $8 \%$ cement mixing ratio is under $200 \mathrm{kPa}$ confining pressure Figure 1 (a), (b) and (c) show that the softening and dilatancy is weakened with confining pressure increasing if cement-mixing ratio is constant. The above-mentioned stress-strain properties are according with conclusions derived from a previous study of cement soil [16].

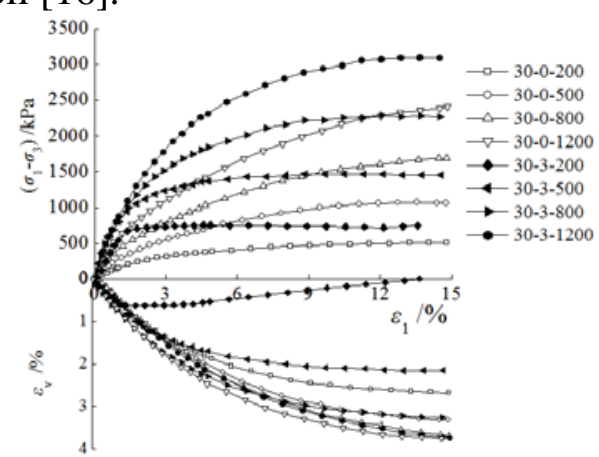

(a) $3 \%$ cement mixing ratio

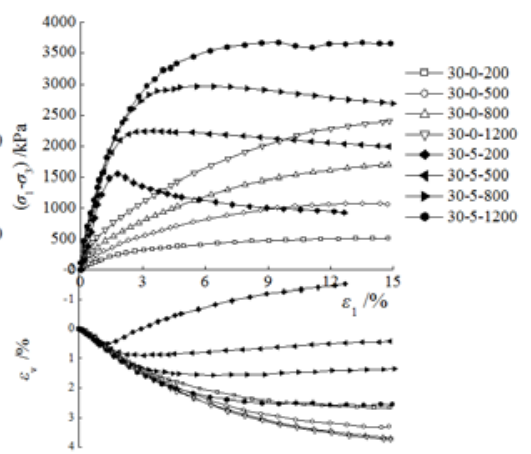

(b) $5 \%$ cement mixing ratio

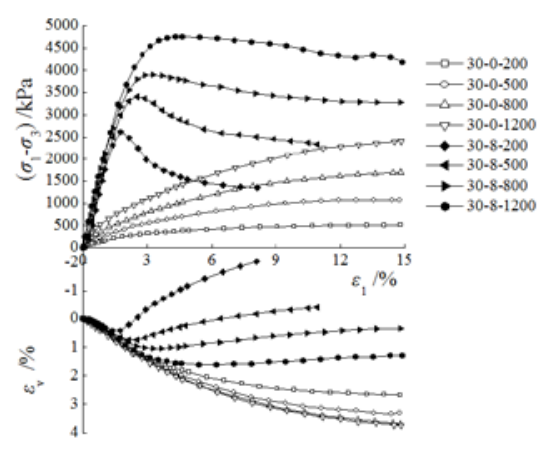

(c) $8 \%$ cement mixing ratio

Fig.1 Curves of $\left(\sigma_{1}-\sigma_{3}\right)-\varepsilon_{\mathrm{a}}-\varepsilon_{\mathrm{V}}$ with different cement ratio

In order to analyze the effect of cement content on the stress-strain properties, the relationships between $\left(\sigma_{1}-\sigma_{3}\right)-\varepsilon_{\mathrm{a}}$, and $\varepsilon_{\mathrm{V}}-\varepsilon_{\mathrm{a}}$ under same confining pressure with cement mixing ratio $w_{\mathrm{c}} 3 \%, 5 \%$ and $8 \%$ (gravel content as 30\%) are shown in Figure 2. For comparison purpose, curves of gravelly soil are also displayed in this figure. 


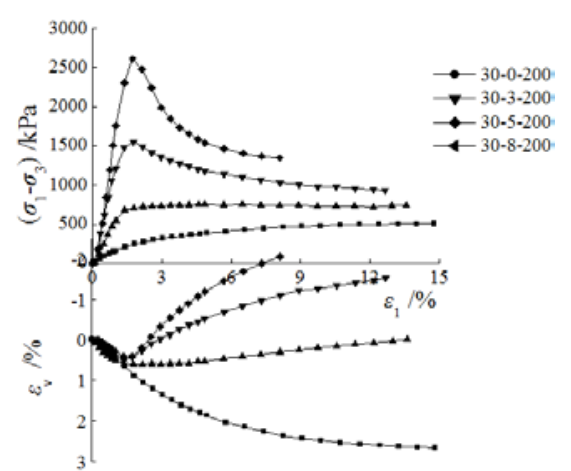

(a) confining pressure as $200 \mathrm{kPa}$

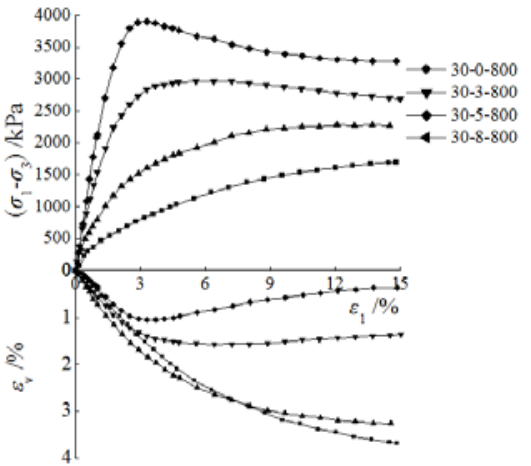

(c) confining pressure as $800 \mathrm{kPa}$

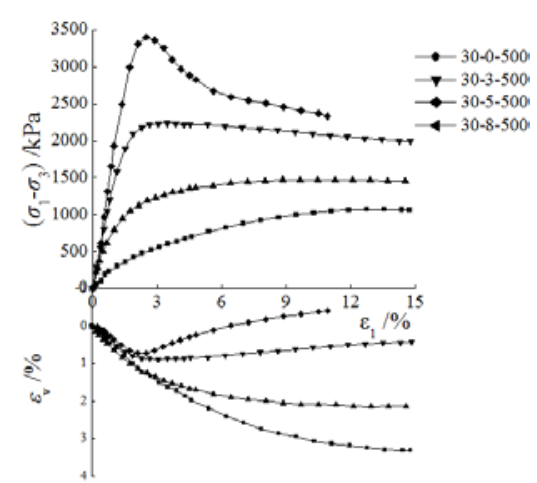

(b) confining pressure as $500 \mathrm{kPa}$

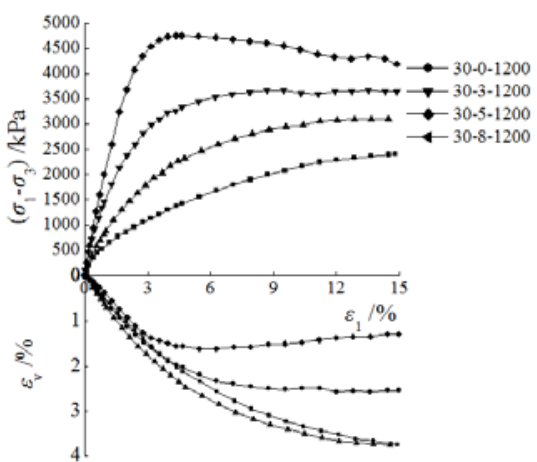

(d) confining pressure as $1200 \mathrm{kPa}$

Fig. 2 Curves of $\left(\sigma_{1}-\sigma_{3}\right)-\varepsilon_{\mathrm{a}}-\varepsilon_{\mathrm{v}}$ under the same $\sigma_{3}$

Figure 2 shows that under different confining pressures, the relationship between $\left(\sigma_{1}-\sigma_{3}\right)$ and $\varepsilon_{\mathrm{a}}$ of gravelly soil shows a hardening type, and the relationship between $\varepsilon_{\mathrm{a}}$ and $\varepsilon_{\mathrm{v}}$ shows shear shrink characteristic.

It can also be seen from Figure 2 that under the same confining pressure, as $w_{\mathrm{c}}$ increasing, the softening phenomenon of stress-strain relationship has been gradually strengthened, which is particularly notable under low levels of confining pressure,. Meanwhile, the dilatancy of samples has been significantly enhanced with an increase of $w_{\mathrm{c}}$.

Under the same confining pressure, as $w_{\mathrm{c}}$ increasing, the axial deviatoric stress (peak shear strength) also increases significantly. Compared to the gravelly soil, the mean peak shear strength with $w_{\mathrm{c}}$ as $3 \%, 5 \%$ or $8 \%\left(\mathrm{M}_{30-3}, \mathrm{M}_{30-5}\right.$ and $\left.\mathrm{M}_{30-8}\right)$ is 1.4 times, 1.7 times, and 2.1times, respectively, of $\mathbf{M}_{30-0}$ (i.e., gravelly soil). This shows that even when cement content is lower, the strength of gravelly soil could be significantly enhanced with the presence of cement.

According to the test results, the peak shear strength of each sample under different confining pressures is arranged as shown in Figure 3. It can be seen from the figure that with the same cement-mixing ratio, the peak shear strength $\left(\sigma_{1}-\sigma_{3}\right)_{f}$ almost increases linearly with confining pressure increasing, and a regression straight line could be drawn directly. It can be seen from Figure 3 that under different cement-mixing ratios, the slope of the line does not change significantly, although the intercept increases significantly with $w_{\mathrm{c}}$ increasing.

Strength characteristics. The Mohr circles and strength envelope corresponding to the failed cases are summarized. Due to similar results, only the results of $\mathbf{M}_{30-8}$ are presented (shown in Figure 4). It can be seen from the figure that the envelope is almost linear. Therefore, the strength of cement-gravel soil in the present paper can be defined according to the Mohr-Coulomb criterion. Also, the strength parameter is linear and independent of confining pressure.

Strength parameters are summarized below: cohesion values are 91.2, 153.5, 417.4 and $757.9 \mathrm{kPa}$, and values of internal friction angle are $25.0^{\circ}, 28.4^{\circ}, 26.9^{\circ}$ and $26.4^{\circ}$, which correspond to $\mathrm{M}_{30-0}$, $\mathrm{M}_{30-3}, \mathrm{M}_{30-5}$, and $\mathrm{M}_{30-8}$ tests, respectively. Compared to gravelly soil, the internal friction angle increases slightly with an increase of cement mixing ratio. Also, the cohesion value also increases significantly with an increase of cement content (e.g., cohesion value of $\mathrm{M}_{30-8}$ is 8.3 times that of $\left.\mathrm{M}_{30-0}\right)$. 

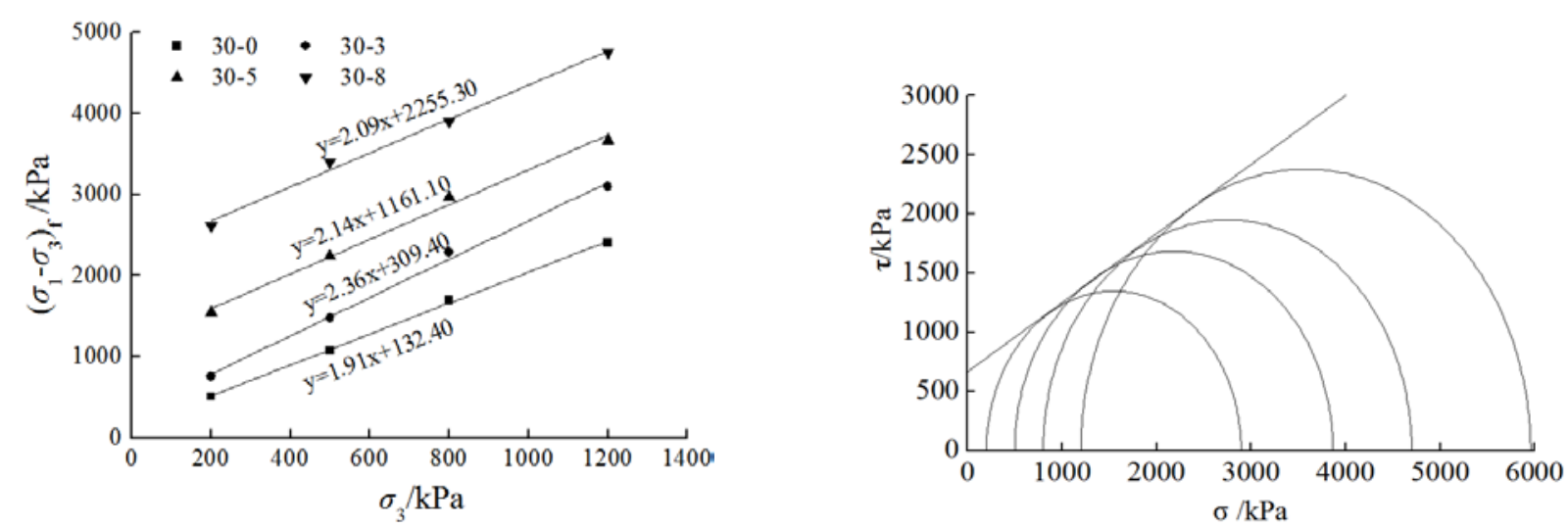

Fig.3 Relationship between $\left(\sigma_{1}-\sigma_{3}\right)_{f}$ and $\sigma_{3} \quad$ Fig. 4 Mohr circles and intensity envelope for $\mathrm{M}_{30-8}$

Deformations. Secant modulus $E_{1}$ (modulus with $1 \%$ axial strain) and $E_{50}$ (modulus with $50 \%$ peak stress) with the variation of cement mixing ratio $w_{\mathrm{c}}$ are presented in Figure 5.

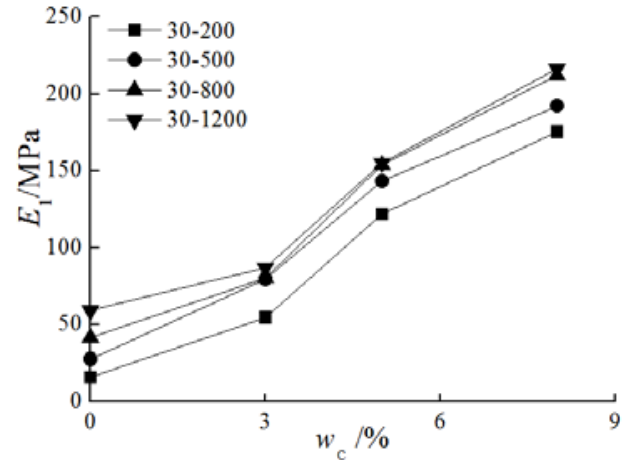

(a) Secant modulus $E_{1}$

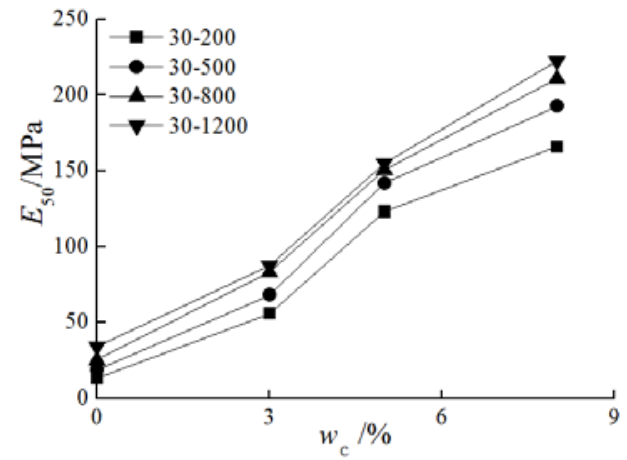

(b) Secant modulus $E_{50}$

Fig.5 Curves of secant moduli vs. cement ratio

It can be seen from Figure 5 that under different confining pressures, both $E_{1}$ and $E_{50}$ increases with an increase of confining pressure. Under $200 \mathrm{kPa}$ confining pressure, $E_{1}$ and $E_{50}$ values of $\mathrm{M}_{30-8}$ is 11.2 and 12.6 times those of $\mathrm{M}_{30-0}$, respectively. But under $1200 \mathrm{kPa}$ confining pressure, $E_{1}$ and $E_{50}$ values of $\mathrm{M}_{30-8}$ is 3.7 and 6.5 times those of $\mathrm{M}_{30-0}$, respectively.

In order to have a more precise determination of the deformation of cement-gravel soil, the volumetric modulus is required. Therefore, the volumetric modulus is specifically studied.

Given the triaxial CD experiment, the volumetric modulus $K_{1}=\left(\sigma_{1}-\sigma_{3}\right) / \varepsilon_{\mathrm{v}}$ can be defined as axial deviatoric stress and volumetric strain (corresponding to $1 \%$ axial strain), which is similar to $E_{1}$. $K_{1}$ is termed as secant volumetric modulus in the presence of $1 \%$ axial strain. The relationship between $K_{1}$ and $w_{\mathrm{c}}$ is presented in Figure 6.

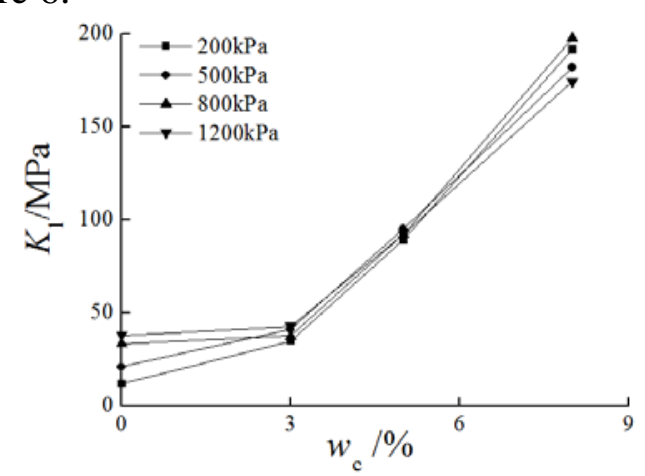

Fig.6 Curves of $K_{1}-w_{\mathrm{c}}$ at different confining pressures

It can be seen from Figure 6 that the volumetric modulus $K_{1}$ increases significantly with an increase of cement mixing ratio. Under $200 \mathrm{kPa}$ confining pressure, $K_{1}$ of $\mathrm{M}_{30-8}$ is 16.5 times that of $\mathrm{M}_{30-0}$. However, $K_{1}$ shows little change when confining pressure varies.

As mentioned earlier, since the brittleness of material increases after the addition of cement, the permeability property after shear failure deserves further study. From test results in earlier sections, 
the shear shrinkage phenomenon is observed when cement content is low and confining pressure is high. Obviously, more studies are required to verify that permeability is unlikely to increase after shear failure events.

\section{Conclusions}

Under different confining pressures, the stress-strain curve of gravelly soil is a hardening type. The stress-strain behavior of cement-gravel soil experiences a softening trend with cement mixing ratio increasing. The softening process is obvious in the presence of high cement mixing ratio $\left(w_{\mathrm{c}}=8 \%\right)$ and low confining pressure $(200 \mathrm{kPa})$.

Under the same confining pressure, the shear dilatancy of cement-gravel soil becomes obvious with an increase of cement mixing ratio. However, the shear dilation subsides with an increase of confining pressure under the constant cement mixing ratio.

Cement content has a significant effect on strength parameters of cement-gravel soil, especially cohesion. By contrast, its impact on the internal friction angle is unremarkable.

The deformation modulus increases significantly after gravelly soil are mixed with cement. Both the secant elastic modulus and the volumetric modulus significantly increase with the increase of cement mixing ratio.

\section{Acknowledgements}

We wish to thank Prof. Jungao Zhu for his assistance.This study was supported by Yellow River Institute of Hydraulic Research, YRCC(No. HKY-JBYW-2014-03). Grateful appreciation is expressed for this support.

\section{References}

[1] Li, G. Y., Wang, L. S. and Mi, Z. K., Research on stress-strain behavior of soil core rockfill dam, Chinese Journal of Geotechnical Engineering. 23(2004), 1369-1369.

[2] Zhu, J. G. and Wang J. J., Investigation to arching action and hydraulic fracturing of core rockfill dam, Proceedings of the 4th International Conference on Dam Engineering. Nanjing, China, 1171-1180, 2004.

[3] Chen, Z. B., Zhu J. G., and Wang Q., Compaction property of wide grading gravelly soil, Chinese Journal of Geotechnical Engineering. 30(2008), 446-449.

[4] Zhang, H., Zhu, J. G., Wang, J. J., et al., Expriment study of tensile strength of compacted gravel soil, Chinese Journal of Geotechnical Engineering. 25(2006), 4177-4190.

[5] Zhu, J. H., You, F., and Yang, K. H., Permeability soil for embankment dam construction, Chinese Journal of Geotechnical Engineering. 15(1993), 18-27.

[6] Qu, Z. J., Application of wide grading gravelly soil as impervious material for the earth and rock-fill dam and its future on seepage control, Design of Hydroelectric Power Station. 8(1992), 46-53.

[7] Chen, Z. B. and Zhu, J. G., Three-dimensional finite element analysis on stress-strain and materials parameters sensibility of Lianghekou core rockfill dam, Journal of Fuzhou University(Natural Science Edition). 38(2010), 893-899.

[8] Wu, M. X., Du, B., Yao, Y. C., et al., Triaxial tests and a new constitutive model of hardfill material, Rock and Soil Mechanics, 32(2011), 2241-2250.

[9] Younoussa, M., Mohamed, H., Raguilnaba, O., et al., Cement-lateritic gravels mixtures: Microstructure and strength characteristics original, Research Article Construction and Building Materials. 22(2008), 2078-2086.

[10]Lonani, T. N., Kongsukprasert, L., Watanabe, K., et al., Strength and deformation properties of compacted cement-mixed gravel evaluated by triaxial compression tests, Soils and Foundations. 44(2004), 99-108.

[11]Wang, Q. Y., Sun W. G. and Xiong H., Plastic concrete for cut off wall[in Chinese], China 
Water \& Power Press ,Beijing, 2008.

[12]Yü, Y. Z., Pu, J. L. and Liu, F. D., Study on mechanical properties of plastic concrete for cut off wall, Journal of Hydraulic Engineering. 39(1995), 21-28.

[13]Yü, Y. Z., Pu, J. L. and Keizo U., Study of mechanical properties of soil-cement mixture for a cut-off wall, Soils and Foundations. 37(1997), 93-103.

[14]Wang, Y. C., Li, J. Z., Zhu G. M., et al., Characterisitics of plastic concrete for impervious core wall of TGP cofferdam II, Journal of Yangtze River Scientific Research Institute. 18(2001), 31-34.

[15]SL237 - 1999, Specification of soil test[in Chinese], China Water \& Power Press ,Beijing.

[16]Hao, J. T., Discussion of the Ideal Mechanical Feature for cement-soil, Chinese Journal of Geotechnical Engineering. 13(1991), 53-59. 